\title{
Control of Lactate Production by Selenomonas ruminantium: Homotropic Activation of Lactate Dehydrogenase by Pyruvate
}

\author{
By R. J. WA LLACE \\ The Rowett Research Institute, Bucksburn, Aberdeen AB2 9SB
}

(Received 12 December 1977)

\begin{abstract}
Selenomonas ruminantium produced one mole of $\mathrm{D}(-)$-lactate per mole of glucose used at all dilution rates in ammonia-limited continuous culture. In contrast, lactate production varied according to the dilution rate when glucose was the limiting nutrient. At dilution rates of less than $0.2 \mathrm{~h}^{-1}$, acetate and propionate were the main fermentation products and lactate production was low. At dilution rates above $0.2 \mathrm{~h}^{-1}$, the pattern changed to one of high lactate production similar to that under ammonia limitation. Experiments with cell-free extracts of $S$. ruminantium showed that $\mathrm{D}(-)$-lactate dehydrogenase had sigmoidal kinetics consistent with homotropic activation of the enzyme by its substrate, pyruvate. This feature allows $S$. ruminantium to amplify the effects of relatively small changes in the intracellular concentration of pyruvate to cause much larger changes in the rate of production of lactate. Some confirmation that this mechanism of control occurs under physiological conditions was obtained in glucose-limited culture, in which the sigmoidal increase in lactate production was accompanied by a linear increase in pyruvate excretion as the dilution rate increased.
\end{abstract}

\section{INTRODUCTION}

The pattern of fermentation products of Selenomonas ruminantium growing on glucose in continuous culture changes according to the dilution rate $(D)$. As $D$ increases, lactate tends to replace acetate and propionate in the extracellular medium (Hobson, 1965 $a$; Scheifinger, Latham \& Wolin, 1975), until, as in strain GA192 of Scheifinger et al. (1975), lactate may become the sole fermentation product.

Regulation of the lactate dehydrogenase (LDH) of several micro-organisms, including the rumen bacteria Streptococcus bovis (Wolin, 1964) and Butyrivibrio fibrisolvens (van Gylswyk, 1977), is achieved by fructose 1,6-bisphosphate being an obligatory activator of the enzyme, so that cells can respond to an accumulation of glycolytic intermediates by activation of $\mathrm{LDH}$ and removal of pyruvate by conversion to lactate, thereby regenerating $\mathrm{NAD}^{+}$. A similar type of control was suspected for $S$. ruminantium by Scheifinger et al. (1975) on the basis of observed differences in fermentation products at different dilution rates, but no activation of LDH by fructose 1,6-bisphosphate was found.

In view of the probable importance of lactate in interspecies cross-feeding in the rumen, and the role of $S$. ruminantium in this activity (Wolin, 1975), the regulation of lactate production of $S$. ruminantium was re-examined in carbon- and nitrogen-limited continuous cultures. Control was again found to be exerted at $\mathrm{LDH}$, but in this bacterium the enzyme was subject to homotropic activation by its substrate, pyruvate, rather than to activation by fructose 1,6-bisphosphate. 


\section{METHODS}

Organism. Selenomonas ruminantium WPL 151/1 was isolated in this Institute from the rumen of a barleyfed sheep by S. O. Mann. This strain was an obligate anaerobe and did not use DL-lactate as a growth substrate. It was maintained by weekly subculture in the liquid form of medium 1 of Kurihara et al. (1968).

Continuous culture. The growth medium contained (per litre final volume): minerals solutions $(a)$ and $(b)$ (Hobson, 1969), $150 \mathrm{ml}$ each; trace metals (Clark \& Holms, 1976), $10 \mathrm{ml} ; 0.075 \%$ (w/v) resazurin, $4 \mathrm{ml}$; vitamins solution, a 10 -fold concentration of the vitamin content of the complete medium of Scott $\&$ Dehority (1965), $100 \mathrm{ml}$; glucose, $20 \mathrm{mmol}$; ammonium chloride, $10 \mathrm{mmol}$ in glucose-limited culture or $1.2 \mathrm{mmol}$ in ammonia-limited culture; reducing solution, $100 \mathrm{ml}$. Reducing solution contained (in boiled, $\mathrm{CO}_{2}$-gassed distilled water): $4 \%(\mathrm{w} / \mathrm{v}) \mathrm{NaHCO}_{3} ; 0.25 \%(\mathrm{w} / \mathrm{v}) \mathrm{Na}_{2} \mathrm{~S} ; 0.25 \%(\mathrm{w} / \mathrm{v}) \mathrm{Na}_{2} \mathrm{~S}_{2} \mathrm{O}_{4}$. It was prepared immediately before use and was sterilized by filtration. Minerals solutions and trace metals were prepared in batches, autoclaved at $121^{\circ} \mathrm{C}$ for $15 \mathrm{~min}$ and stored at $4{ }^{\circ} \mathrm{C}$ until required. Vitamins solution was sterilized by filtration and stored at $4{ }^{\circ} \mathrm{C}$. Other solutions were prepared fresh.

All constituents of the medium apart from the reducing solution were mixed with boiled, glass-distilled water and autoclaved in 51 batches $\left(109^{\circ} \mathrm{C}, 45 \mathrm{~min}\right)$. The reducing solution was then added and the reservoir was gassed by the method of Hobson $(1965 b)$.

Continuous culture apparatus was based on the system developed by Hobson (1965 $b$ ) and Hobson \& Summers (1967), and modified so that peristaltic pumps delivered growth medium (MHRE 22; WatsonMarlow, Falmouth, Cornwall) and $1 \mathrm{M}-\mathrm{NaOH}$ for $\mathrm{pH}$ control (Minipump; Schuco Scientific, London). Samples were removed from the culture by a sampling hood similar to that described by Baker (1968) except that anaerobic conditions were maintained. The culture volume was 100 or $300 \mathrm{ml}$, depending on the dilution rate required.

Samples were taken from the culture after a minimum flow of 5 culture volumes; these were immediately chilled on ice, and a portion of each was centrifuged $\left(3000 \mathrm{~g}, 4^{\circ} \mathrm{C}, 15 \mathrm{~min}\right)$. Culture supernatants were stored at $-20^{\circ} \mathrm{C}$ and pellets at $-60^{\circ} \mathrm{C}$. No attempt was made to exclude air from samples.

Analyses. Glucose in the inflowing medium and in the supernatant fluid from centrifuged culture samples was determined in an automatic analyser by the glucose oxidase method (Morley, Dawson \& Marks, 1968). Lactate was measured by the microdiffusion method of Conway (1957), in which lactate is non-stereospecifically oxidized to acetaldehyde by ceric sulphate. $\mathbf{L}(+)$-Lactate was assayed using $\mathbf{L}(+)$-lactate dehydrogenase (Boehringer). Acetate and propionate were determined directly on acidified culture supernatants by the gas chromatography method of Fell et al. (1968) with peak areas estimated using a Pye Unicam DP80 digital integrator. A standard solution of $30 \mathrm{~mm}$-acetate and $10 \mathrm{~mm}$-propionate was used for calibration. The lactate dehydrogenase assay of Kubowitz \& Ott (1943) was adapted for the measurement of pyruvate: samples were incubated in a $1 \mathrm{ml}$ assay mixture containing $42 \mu \mathrm{mol} \mathrm{KH}_{2} \mathrm{PO}_{4}, 0 \cdot 2 \mathrm{mg} \mathrm{NADH}$, and $10 \mu$ lactate dehydrogenase $\left(5 \mathrm{mg} \mathrm{ml}^{-1}\right)$ at $\mathrm{pH} 7 \cdot 4$, and pyruvate was estimated from the $\Delta A_{340}$. Succinate was assayed by the method of Clark \& Porteous (1964). The protein content of cell-free extracts was determined by the method of Lowry et al. (1951) using bovine serum albumin as a standard. Cell density was calculated from the turbidity at $650 \mathrm{~nm}$ of diluted samples from cultures, measured using a Pye Unicam SP600 spectrophotometer. The standard curve of turbidity against dry weight was linear up to an absorbance of 1.0 , and samples were diluted to an absorbance of less than 0.7 for estimation of cell density. Washed cell suspensions were dried at $105^{\circ} \mathrm{C}$ overnight for calibration of the dry weight/turbidity relationship.

Preparation of cell-free extracts. Pellets from continuous culture samples were resuspended in cold $30 \mathrm{~mm}-$ $\mathrm{KH}_{2} \mathrm{PO}_{4}$ buffer $\mathrm{pH} 7 \cdot 0$ and disrupted using a Soniprobe (Dawe Instruments, London) at a current of $5 \mathrm{~A}$ for $5 \mathrm{~min}$, with alternate $30 \mathrm{~s}$ on/off periods. The sample was kept on ice throughout. Whole cells were removed by centrifugation $\left(11600 \mathrm{~g}, 4^{\circ} \mathrm{C}, 1 \mathrm{~h}\right)$ and the supernatant liquid was either used immediately or stored at $-60^{\circ} \mathrm{C}$.

Lactate dehydrogenase. LDH activity was assayed in cell-free extracts by measurement of the rate of NADH oxidation at $340 \mathrm{~nm}$, using a Pye Unicam SP1 800 spectrophotometer. The assay mixture, incubated at $25{ }^{\circ} \mathrm{C}$, contained (in $3 \mathrm{ml}$ ) : $60 \mu \mathrm{mol} \mathrm{KH}_{2} \mathrm{PO}_{4}$ buffer $\mathrm{pH} 7 \cdot 0 ; 0.75 \mu \mathrm{mol} \mathrm{NADH} ; 50 \mu$ mol sodium pyruvate; $0.5 \mathrm{ml}$ cell-free extract. The reaction was started by addition of NADH. NADH oxidase was estimated from the rate of $\mathrm{NADH}$ oxidation in the absence of pyruvate, and this value was subtracted from the total initial rate of $\mathrm{NADH}$ oxidation to give $\mathrm{LDH}$ activity.

NAD-independent LDH activity was assayed using phenazine methosulphate and 2,6-dichlorophenolindophenol (Gregolin \& Singer, 1963).

Chemicals. Pyridoxin. $\mathrm{HCl}$, thiamin.HCl, NADH, NADPH, NAD ${ }^{+}$, DL-lactic acid, fructose 1,6-bisphosphate, AMP, bovine serum albumin, ATP, phenazine methosulphate, 2,6-dichlorophenolindophenol, Trizma base and imidazole were obtained from Sigma, L(+)-lactate dehydrogenase (EC 1.1.1.27), glucose 6-phosphate and ADP from Boehringer, and sodium dithionite from May \& Baker. All other chemicals were obtained from BDH. 


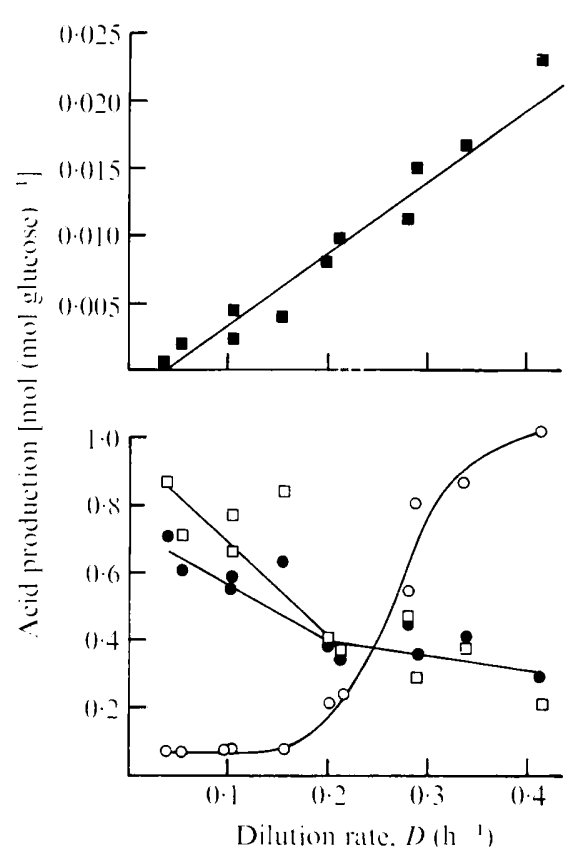

Fig. 1

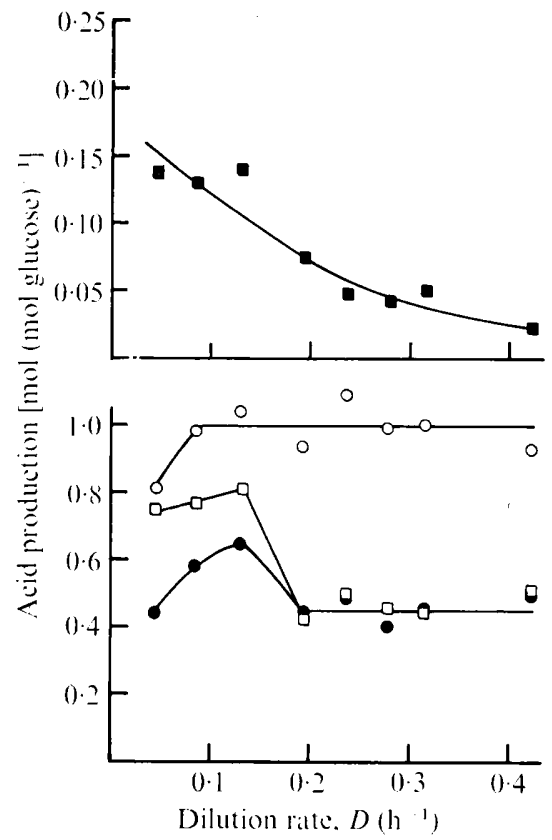

Fig. 2

Fig. 1. Fermentation products in glucose-limited continuous culture: $\bigcirc$, lactate; $\odot$, acetate; $\square$, propionate; $\square$, pyruvate.

Fig. 2. Fermentation products in ammonia-limited continuous culture: symbols as in Fig. 1.

\section{RESULTS}

\section{Production of fermentation acids in continuous culture}

Selenomonas ruminantium produced acetate, propionate and lactate at all dilution rates in both glucose- and ammonia-limited continuous cultures. However, the rate of production of each acid varied according to the limiting substrate and the dilution rate.

Under glucose limitation (Fig. 1), production of lactate was low at low dilution rates, and rose slowly up to $D=0 \cdot 2 \mathrm{~h}^{-1}$. Thereafter lactate production increased rapidly, eventually reaching 1.0 mole of lactate per mole of glucose consumed at $D=0.41 \mathrm{~h}^{-1}$. The maximum specific growth rate of $S$. ruminantium is $0.44 \mathrm{~h}^{-1}$ in this medium. Production of acetate and propionate fell with increasing dilution rate (Fig. 1). Succinate was a minor product often detected in the medium, but its production was variable, and in any case was always less than $4 \%$ of the glucose carbon fermented. Production of pyruvate, another minor fermentation product, increased linearly with dilution rate (Fig. 1). No butyrate was found in any sample. Carbon balances were constructed, making the assumption that carbon constituted $50 \%$ of the dry weight of bacteria. At all values of $D$ except $0 \cdot 20$ and $0 \cdot 21 \mathrm{~h}^{-1}$, cell material, acetate $\left(+\mathrm{CO}_{2}\right)$, propionate, lactate, succinate $\left(-\mathrm{CO}_{2}\right)$ and pyruvate accounted for $102 \cdot 0 \pm 4 \cdot 5 \%$ of the glucose carbon consumed. At $D=0 \cdot 20,0 \cdot 21 \mathrm{~h}^{-1}$, recovery of carbon in the above products fell to $84 \cdot 1$ and $77.4 \%$ respectively.

Under ammonia limitation (Fig. 2), lactate production was high throughout. The production of pyruvate was also generally higher than under glucose limitation; however, under ammonia limitation, pyruvate production fell as $D$ increased, until at values of $D$ near the maximum specific growth rate, its yield [about $23 \mathrm{mmol}(\mathrm{mol} \text { glucose })^{-1}$ ] was similar in both types of culture, as was lactate production. The formation of acetate and propionate in ammonia-limited cultures was independent of dilution rate above $D=0.19 \mathrm{~h}^{-1}$, but at lower $D$ the production of these acids, particularly of propionate, did change with 
Table 1. Lactate dehydrogenase content and rate of lactate production of S. ruminantium

Samples were removed from continuous cultures, harvested, sonicated and assayed for LDH as described in Methods. Specific activity of LDH in cell-free extracts is expressed in $\mu$ mol NADH oxidized (mg protein) $)^{-1} \mathrm{~h}^{-1}$. The production of lactate is expressed both as concentration and as the specific rate of production by the culture, in $\mu \mathrm{mol}$ lactate (mg dry wt) $)^{-1} \mathrm{~h}^{-1}$.

$\begin{array}{lcccc}\begin{array}{c}\text { Limiting } \\ \text { nutrient }\end{array} & D\left(\mathrm{~h}^{-1}\right) & \begin{array}{c}\text { Specific activity } \\ \text { of LDH }\end{array} & \begin{array}{c}\text { Lactate concn } \\ (\mathrm{mM})\end{array} & \begin{array}{c}\text { Rate of lactate } \\ \text { production }\end{array} \\ \text { Glucose } & 0 \cdot 15 & 28 & 1 \cdot 3 & 0 \cdot 3 \\ \text { Glucose } & 0 \cdot 18 & 11 & 1 \cdot 5 & 0 \cdot 9 \\ \text { Glucose } & 0 \cdot 21 & 19 & 4 \cdot 3 & 0 \cdot 9 \\ \text { Glucose } & 0 \cdot 29 & 15 & 13 \cdot 5 & 6 \cdot 7 \\ \text { Glucose } & 0 \cdot 34 & 19 & 15 \cdot 6 & 7 \cdot 3 \\ \text { Ammonia } & 0 \cdot 05 & 4 & 9 \cdot 3 & 1 \cdot 7 \\ \text { Ammonia } & 0 \cdot 13 & 4 & 6 \cdot 9 & 7 \cdot 1 \\ \text { Ammonia } & 0 \cdot 22 & 7 & 6 \cdot 8 & 26 \cdot 5 \\ \text { Ammonia } & 0 \cdot 32 & 12 & 5 \cdot 3 & 21 \cdot 0\end{array}$

Table 2. Effects of some potential regulators of lactate dehydrogenase activity

The overflow from an ammonia-limited culture $\left(D=0.39 \mathrm{~h}^{-1}\right)$ was collected at $4{ }^{\circ} \mathrm{C}$ and harvested by centrifugation $\left(11600 \mathrm{~g}, 4^{\circ} \mathrm{C}, 15 \mathrm{~min}\right)$. A cell-free extract was prepared and $\mathrm{LDH}$ was assayed as described in Methods. Activities are expressed as percentages of the rate of NADH oxidation in the absence of added potential effectors. The standard error of the mean of four replicate assays was always less than $\pm 7 \%$ of the full $\mathrm{LDH}$ activity.

Addition

None

Fructose 1,6-bisphosphate

Glucose 6-phosphate

$\mathrm{NAD}^{+}$

AMP

ADP

ATP

ATP

ATP

Fumarate

Succinate

$\begin{array}{cc}\begin{array}{c}\text { Concn } \\ (\mathrm{mM})\end{array} & \begin{array}{c}\text { LDH activity } \\ (\%)\end{array} \\ - & 100 \\ 0.5 & 100 \\ 1 \cdot 0 & 98 \\ 1 \cdot 0 & 84 \\ 1 \cdot 0 & 111 \\ 1 \cdot 0 & 75 \\ 0 \cdot 4 & 72 \\ 1 \cdot 0 & 46 \\ 2 \cdot 0 & 49 \\ 5 \cdot 0 & 97 \\ 5 \cdot 0 & 99\end{array}$

changing $D$. An unusually high recovery of carbon was associated with ammonia-limited cultures. For $D \geqslant 0.19 \mathrm{~h}^{-1}$ the recovery was $112.1 \pm 3.8 \%$, and at $D<0.19 \mathrm{~h}^{-1}$ the apparent recovery of carbon was even greater (e.g. $158 \%$ at $D=0.13 \mathrm{~h}^{-1}$ ). Again, succinate was a variable minor fermentation product in most samples.

While lactate was measured routinely by the non-stereospecific method of Conway (1957), several samples from both types of culture at several dilution rates were analysed by the stereospecific enzymic method. No $\mathrm{L}(+)$-lactate was found in the supernatant fluid from any culture sample.

\section{Properties of lactate dehydrogenase of S. ruminantium}

NAD-linked LDH activity was measured in the supernatant fraction of centrifuged, sonicated samples from continuous cultures. The LDH of glucose- and ammonia-limited $S$. ruminantium at different dilution rates varied (Table 1), but not in a way which accounted for the observed differences in the rates of lactate production in continuous culture.

Enzyme activity was stable to freezing, both of whole bacteria and of sonicated samples, and on storage at $-60^{\circ} \mathrm{C}$ for several weeks. It was also completely stable in sonicated samples at room temperature for at least $6 \mathrm{~h}$. NADP could not replace NAD as cofactor for the enzyme, and the product was $\mathrm{D}(-)$-lactate. No activity was associated with the particulate 

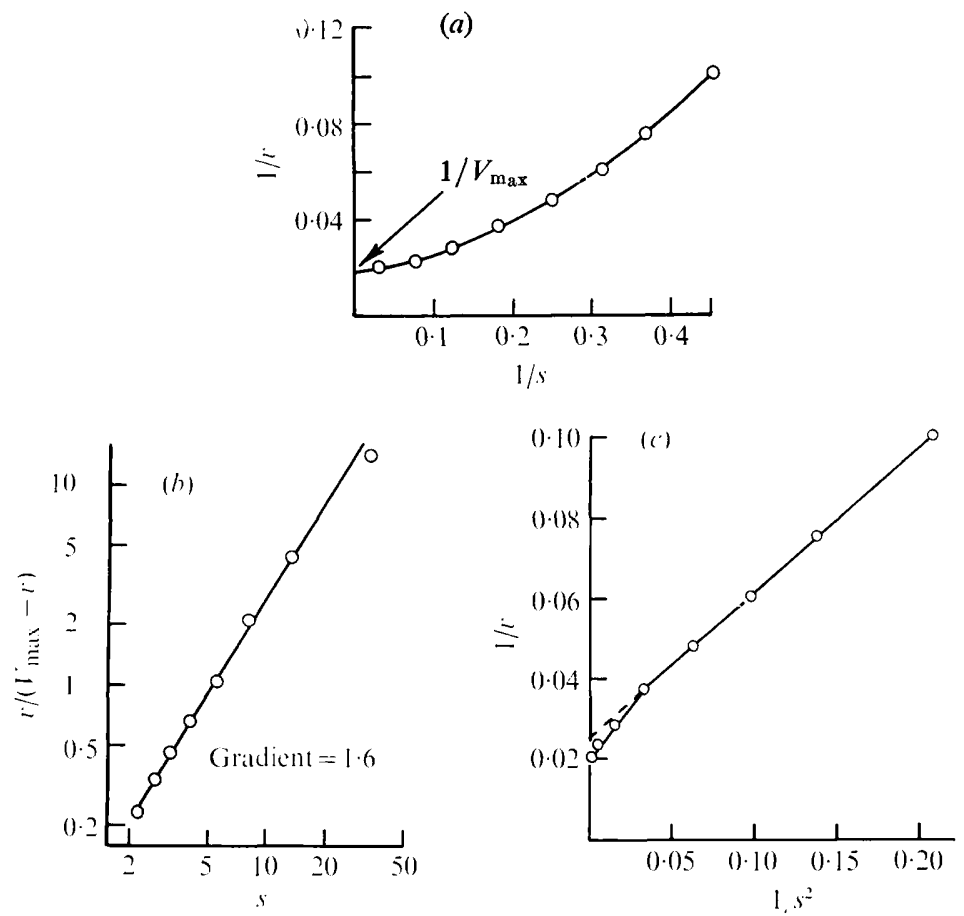

Fig. 3. Influence of pyruvate concentration on lactate dehydrogenase activity. The overflow from an ammonia-limited continuous culture was collected at $4^{\circ} \mathrm{C}$ and harvested by centrifugation $(11600 \mathrm{~g}$, $\left.4{ }^{\circ} \mathrm{C}, 15 \mathrm{~min}\right)$. A cell-free extract was prepared and LDH was assayed as described in Methods. Each assay mixture contained $138 \mu \mathrm{g}$ protein. Results are expressed in terms of the initial rate of NADH oxidation $\left[v ; \mu\right.$ mol NADH oxidized $\left.(\mathrm{mg} \text { protein })^{-1} \mathrm{~h}^{-1}\right]$ and pyruvate concentration $(s ; \mathrm{mm})$. (a) Lineweaver-Burk double reciprocal plot. (b) Hill plot, using $V_{\max }$ determined from plot $(a)$.

(c) Double reciprocal plot: $1 / v$ against $1 / s^{2}$.

fraction. NAD-independent LDH activity in whole sonicated samples was less than $2 \%$ of the NAD-linked activity. Fructose 1,6-bisphosphate did not affect NAD-independent LDH.

Several potentially regulatory compounds were tested for their effects on LDH activity (Table 2). Of these, ATP and, to a lesser extent, ADP and NAD ${ }^{+}$caused inhibition, while fructose 1,6-bisphosphate, glucose 6-phosphate, AMP, fumarate and succinate had no significant effect. Fructose 1,6-bisphosphate also did not activate $\mathrm{LDH}$ in assays in which $20 \mathrm{~mm}$-Tris pH 7.6 replaced phosphate as the buffer in which bacteria were disrupted and in which $\mathrm{LDH}$ was assayed.

\section{Enzyme kinetics}

LDH activity was measured over a range of pyruvate concentrations, and the results were graphed in several ways. A Lineweaver-Burk plot of the data was clearly non-linear (Fig. $3 a$ ), and a Hill plot (Fig. $3 b$ ) confirmed that the disproportionately low activity of LDH at low pyruvate concentrations was a consequence of a cooperative effect of the substrate on enzyme activity. For the experiment illustrated by Fig. 3, the Hill coefficient was 1.6 and the substrate concentration at $\frac{1}{2} V_{\max }$ [i.e. where $v /\left(V_{\max }-v\right)=1$ ] was $5.4 \mathrm{~mm}$. A double reciprocal plot of $1 / v$ against $1 / s^{2}$ (Fig. $3 c$ ) gave a graph that was linear except at the highest concentrations of pyruvate.

The kinetic experiment was repeated using cell-free extracts from other glucose- and ammonia-limited cultures at different growth rates, with very similar results. Hill coefficients were similar, and again the $1 / v$ against $1 / s^{2}$ graph appeared linear at all but the highest values of $s$. 


\section{DISCUSSION}

Hobson (1965a) and Scheifinger et al. (1975) observed that the fermentation pattern of $S$. ruminantium changed according to the dilution rate in glucose-limited continuous culture, such that acetate and propionate production fell as $D$ increased and lactate became an increasingly predominant product. Their results did not, however, show that the increase was in two phases and that a transition from low lactate production to high lactate production took place at around $D=0 \cdot 2 \mathrm{~h}^{-1}$. Ammonia-limited continuous culture, where carbon and energy were presumably in excess at all $D$ values and lactate production was always high, complemented glucose-limited culture in support of the suggestion by Scheifinger et al. (1975) that the activity of LDH might be regulated by levels of intracellular pools of metabolic intermediates, such that accumulation of metabolites would activate LDH and trigger conversion of pyruvate to lactate. The possibility that LDH activity was controlled by regulation of the enzyme's synthesis was eliminated since no correlation was found between the LDH content of cultures and their lactate-producing activity.

Lactate dehydrogenases of a wide range of life forms are subject to metabolic regulation (Everse \& Kaplan, 1973), and those of several micro-organisms require fructose 1,6-bisphosphate for activation (Wolin, 1964; de Vries et al., 1970; Jonas, Anders \& Jago, 1972; Holland \& Pritchard, 1975; Eisenberg, Elchisak \& Rudd, 1976; van Gylswyk, 1977; Crow \& Pritchard, 1977). However, as also found by Scheifinger et al. (1975), the LDH of $S$. ruminantium showed no response to added fructose 1,6-bisphosphate. Of some other possible effectors, only ATP significantly influenced enzyme activity, 2 mM-ATP causing more than $50 \%$ inhibition. It seems unlikely that inhibition of LDH by ATP could be primarily responsible for the transition in rates of lactate production discussed above, particularly since the ATP pool of $S$. ruminantium does not change markedly with growth rate (Hobson \& Summers, 1972). It is more likely that ATP is a secondary regulator of LDH, as it is for the fructose 1,6-bisphosphate-activated enzyme in Rothia dentocariosa (Eisenberg et al., 1976) and the pyruvate-activated enzyme of Butyribacterium rettgeri (Wittenberger, 1968), so that LDH is partially inhibited by high energy levels and activated by high levels of intracellular pools of glycolytic intermediates.

The kinetic experiments with cell-free extracts clearly showed that the LDH of S. ruminantium did not display classical Michaelis-Menten kinetics in response to changes in pyruvate concentration. Enzyme activity increased with increasing substrate concentration more rapidly than could be accounted for by simple saturation of a single binding site on the LDH molecule. Analysis of these data by a Hill plot indicated that LDH possessed two binding sites for pyruvate, such that binding of pyruvate to the molecule was positively cooperative and resulted in activation of the enzyme. It was therefore concluded that LDH of S. ruminantium is an allosteric enzyme subject to homotropic activation by its substrate, pyruvate.

The $\mathrm{D}(-)$-lactate dehydrogenases of Butyribacterium rettgeri (Wittenberger \& Fulco, 1967; Wittenberger, 1968) and Escherichia coli в (Tarmy \& Kaplan, 1968) have kinetic properties strikingly similar to those of the LDH of $S$. ruminantium which was also found to be a $\mathrm{D}(-)$-lactate dehydrogenase (EC 1.1.1.28). The enzymes of all three bacteria were allosterically activated by pyruvate, were inhibited by ATP, and were linked specifically to $\mathrm{NAD}^{+}$as cofactor. Indeed the $E$. coli enzyme gave a Hill plot similar to that for S.ruminantium with a gradient of 1.7 (cf. 1.6 for $S$. ruminantium) and a pyruvate concentration at $\frac{1}{2} V_{\max }$ of $7.2 \mathrm{~mm}$ (cf. $5.4 \mathrm{~mm}$ ) at $\mathrm{pH} 7 \cdot 5$. The $B$. rettgeri enzyme had a slightly higher affinity for pyruvate (Wittenberger \& Fulco, 1967), but was otherwise similar.

Tarmy \& Kaplan (1968) pointed out that a consequence of the regulatory characteristics of $E$. coli $\mathrm{LDH}$ was that the reduction of pyruvate to lactate would follow virtually second order reaction kinetics at low concentrations of pyruvate. The graph of $1 / v$ against $1 / s^{2}$ showed that this was also true for the LDH of $S$. ruminantium.

Pyruvate occupies a central position in the metabolism of $S$. ruminantium, at the junction 
between glycolysis and the biosynthetic reactions of fatty acid and amino acid synthesis, the energy-yielding pathways of acetate and propionate production, and lactate production. So that the biosynthetic reactions may continue under all growth conditions, it is essential that LDH should never cause entire depletion] of the pyruvate pool. This is achieved by LDH being inactive or only partially active at low pyruvate concentrations, and only becoming fully active in response to high levels of pyruvate. A similar interpretation of the physiological consequences of this type of kinetic control was made by Tarmy \& Kaplan (1968).

Some confirmation of this reasoning was the relationship found between lactate and pyruvate production in continuous culture. Leakage of pyruvate into the medium, which was presumably a function of intracellular pyruvate concentration, increased linearly with increasing growth rate, yet lactate production was sigmoidal in relation to growth rate. At low $D$, the pyruvate concentration was low, LDH was largely inactive and the proportion of glucose fermented to lactate was minimal. As the pyruvate concentration passed a critical level at $D=0 \cdot 2 \mathrm{~h}^{-1}$, LDH was activated and lactate became the major product. Under ammonia limitation, with the carbon source in excess, the pyruvate pool was always high, and the molar ratio of lactate produced/glucose fermented was approximately 1.0 at all dilution rates.

The recovery of carbon in known products from glucose-limited cultures was complete, except in the region of transition from mainly volatile acid production to mainly lactate production. A similar 'loss' of carbon in glucose-limited cultures of two other strains of $S$. ruminantium can be calculated from the results of Scheifinger et al. (1975), the loss again occurring only at the transition phase in the production of fermentation acids. The fate of this carbon is not known. The cause of the high carbon recovery in ammonia-limited cultures, apparently much greater than $100 \%$, is also unknown, but is not unprecedented in the study of rumen bacteria (e.g. Latham \& Legakis, 1976). As the only sources of carbon other than glucose were $\mathrm{HCO}_{3}-$ in the reducing solution and the $\mathrm{CO}_{2}$ gas phase, it must be concluded that considerable $\mathrm{CO}_{2}$ fixation may occur in ammonia-limited $S$. ruminantium, particularly at low dilution rates where the ATP pool and pools of other metabolic intermediates are likely to be high. $\mathrm{CO}_{2}$ is essential for optimal growth of $S$. ruminantium in batch culture (Dehority, 1971), and it may be that $\mathrm{CO}_{2}$ uptake is, under some circumstances, quantitatively more significant than its virtually catalytic role in the propionate fermentation pathway (Hobson \& Summers, 1972).

It should be noted that some strains of $S$. ruminantium form DL-lactate or only the L $(+)$ isomer (de Vries, van Wijck-Kapteyn \& Oosterhuis, 1974; Scheifinger et al., 1975), and so this mechanism of metabolic control may not be applicable to other strains.

I thank Mrs I. Wood for technical assistance and Drs P. N. Hobson and C. Henderson for helpful discussion.

\section{REFERENCES}

BAKER, K. (1968). Low cost continuous culture apparatus. Laboratory Practice 17, 817-824.

Clark, B. \& Holms, W. H. (1976). Control of the sequential utilization of glucose and fructose by Escherichia coli. Journal of General Microbiology 95, 191-201.

Clark, B. \& Porteous, J. W. (1964). Determination of succinic acid by an enzymic method. Biochemical Journal 93, 21c.

Conway, E. J. (1957). Microdiffusion Analysis and Volumetric Error, 4th edn, pp. 277-278. London: Crosby Lockwood \& Son.

Crow, V. L. \& Pritchard, G. G. (1977). Fructose 1,6-diphosphate-activated L-lactate dehydrogenase from Streptococcus lactis: kinetic properties and factors affecting activation. Journal of Bacteriology 131, 82-91.

Dehority, B. A. (1971). Carbon dioxide requirement of various species of rumen bacteria. Journal of Bacteriology 105, 70-76.

EISENBERG, R. J., ElchisaK, M. \& Rudd, J. (1976). Regulation of lactate dehydrogenase activity in Rothia dentocariosa by fructose 1,6-diphosphate and adenosine 5'-triphosphate. Journal of Bacteriology 126, 1344-1346.

EVERSE, J. \& KaPLAN, N. O. (1973). Lactate dehydrogenases-structure and function. Advances in Enzymology 37, 61-133.

Fell, B. F., Kay, M., Whitelaw, F. G. \& Boyne, R. (1968). Observations on the development of 
ruminal lesions in calves fed on barley. Research in Veterinary Science 9, 458-466.

Gregolin, C. \& Singer, T. P. (1963). The lactic dehydrogenase of yeast. III. D(-)-Lactic cytochrome $c$ reductase, a zinc-flavoprotein from aerobic yeast. Biochimica et biophysica acta 67, 201-218.

VAN GYLSWYCK, N. O. (1977). Activation of NADdependent lactate dehydrogenase in Butyrivibrio fibrisolvens by fructose 1,6-diphosphate. Journal of General Microbiology 99, 441-443.

Hobson, P. N. (1965a). Continuous culture of some anaerobic and facultatively anaerobic rumen bacteria. Journal of General Microbiology 38, 167-180.

Hobson, P. N. (1965b). Continuous culture of rumen bacteria: apparatus. Journal of General Microbiology 38, 161-166.

Hobson, P. N. (1969). Rumen bacteria. Methods in Microbiology 3B, 133-149.

Hobson, P. N. \& Summers, R. (1967). The continuous culture of anaerobic bacteria. Journal of General Microbiology 47, 53-65.

Hobson, P. N. \& Summers, R. (1972). ATP pool and growth yield in Selenomonas ruminantium. Journal of General Microbiology 70, 351-360.

Holland, R. \& Pritchard, G. G. (1975). Regulation of the L-lactate dehydrogenase from Lactobacillus casei by fructose-1,6-diphosphate and metal ions. Journal of Bacteriology 121, 777-784.

Jonas, H. A., ANDERs, R. F. \& JAGO, G. R. (1972). Factors affecting the activity of the lactatedehydrogenase of Streptococcus cremoris. Journal of Bacteriology 111, 397-403.

Kubowitz, F. \& OTT, P. (1943). Isolierung und Kristallisation eines Gärungsfermentes aus Tumoren. Biochemische Zeitschrift 314, 94-117.

Kurihara, Y., Eadie, J. M., Hobson, P. N. \& MANN, S. O. (1968). Relationship between bacteria and ciliate protozoa in the sheep rumen. Journal of General Microbiology 51, 267-288.

LATHAM, M. J. \& LeGaKis, N. J. (1976). Cultural factors influencing the utilization or production of acetate by Butyrivibrio fibrisolvens. Journal of General Microbiology 94, 380-388.

Lowry, O. H., Rosebrough, N. J., FARr, A. L. \& RANDALl, R. J. (1951). Protein measurement with the Folin phenol reagent. Journal of Biological Chemistry 193, 265-275.

Morley, G., Dawson, A. \& Marks, V. (1968).
Manual and autoanalyser methods for measuring blood glucose using guaiacum and glucose oxidase. Proceedings of the Association of Clinical Biochemists 5, 42-45.

Scheifinger, C. C., Latham, M. J. \& Wolin, M. J. (1975). Relationship of lactate dehydrogenase specificity and growth rate to lactate metabolism by Selenomonas ruminantium. Applied Microbiology 30, 916-921.

ScotT, H. W. \& Dehority, B. A. (1965). Vitamin requirements of several cellulolytic rumen bacteria. Journal of Bacteriology 89, 1169-1175.

TARMY, E. M. \& KAPLAN, N. O. (1968). Kinetics of Escherichia coli B D-lactate dehydrogenase and evidence for pyruvate-controlled change in conformation. Journal of Biological Chemistry 243, 2587-2596.

de Vries, W., Kapteijn, W. M. C., van der Beek, E. G. \& Stouthamer, A. H. (1970). Molar growth yields and fermentation balances of Lactobacillus casei $\mathbf{L} 3$ in batch cultures and in continuous cultures. Journal of General Microbiology 63, 333-345.

de Vries, W., van WiJck-Kapteyn, W. M. C. \& OOSTERHuIS, S. K. H. (1974). The presence and function of cytochromes in Selenomonas ruminantium, Anaerovibrio lipolytica and Veillonella alcalescens. Journal of General Microbiology 81, 69-78.

WitTenberger, C. L. (1968). Kinetic studies on the inhibition of a $\mathrm{D}(-)$-specific lactate dehydrogenase by adenosine triphosphate. Journal of Biological Chemistry 243, 3067-3075.

Wittenberger, C. L. \& Fulco, J. G. (1967). Purification and allosteric properties of a nicotinamide adenine dinucleotide-linked $\mathrm{D}(-)$-specific lactate dehydrogenase from Butyribacterium rettgeri. Journal of Biological Chemistry 242, 29172924.

Wolin, M. J. (1964). Fructose-1,6-diphosphate requirement of streptococcal lactic dehydrogenases. Science 146, 775-777.

Wolin, M. J. (1975). Interactions between the bacterial species of the rumen. In Digestion and Metabolism in the Ruminant, Proceedings of the IVth International Symposium on Ruminant Physiology, pp. 134-148. Edited by I. W. McDonald and A. C. I. Warner. Armidale, N.S.W., 2351, Australia: University of New England Publishing Unit. 